\title{
STUDIES ON THE OSMOTIC FRAGILITY OF INCUBATED NORMAL AND ABNORMAL ERYTHROCYTES *
}

\author{
By A. HAUT,$\dagger$ G. R. TUDHOPE, $\ddagger$ G. E. CARTWRIGHT AND M. M. WINTROBE
}

(From the Department of Medicine, University of Utah College of Medicine, Salt Lake City, Utah)

(Submitted for publication March 19, 1962; accepted May 31, 1962)

The osmotic fragility of erythrocytes is known to undergo alterations when whole blood is incubated under aseptic conditions for 24 hours. The osmotic fragility of spherocytes increases considerably (1). Normal erythrocytes undergo a slight increase in fragility (2) and by contrast the osmotic fragility of leptocytes and certain other erythrocytes (3) is decreased. The sequence of events associated with this divergent change and the factors which influence it are the subjects of this study.

Under certain circumstances the normal erythrocyte may behave as an osmometer (4). Though not implying "rupture" of the erythrocyte (5), osmotic lysis occurs when the red cell volume increases to a critical value $(6,7)$. In in vitro systems, the degree of osmotic lysis which may occur is affected by $\mathrm{pH}$, temperature, and tonicity (8) of the surrounding medium. If these variables are held constant, then alterations in the osmotic fragility of the incubated erythrocytes would reflect changes in their milien interne which result from metabolic activity during incubation.

Abnormality of shape or volume of erythrocytes or both is presumed to alter their osmotic fragility by virtue of altering the span between the initial volume and the critical hemolytic volume of the cell $(6,7,9)$. However, abnormal cell geometry does not, by this means, account for the apparent paradoxical response of the osmotic fragility of leptocytes to incubation. If the initial direction of change in the osmotic fragility of incubated leptocytes were abnormal, an abnormality of erythrocyte metabolism would be suggested. If the initial change in osmotic fragility were normal but

* This investigation was supported by a research grant (A-4489) from the National Institute of Arthritis and Metabolic Diseases, U. S. Public Health Service.

$\dagger$ Markle Scholar in Medical Science.

$\ddagger$ Lederle Traveling Fellow (1959-1960) on leave from the Department of Pharmacology and Therapeutics, University of Sheffield. the timing of sequential events were abnormal, as suggested by earlier observations at 24 and 48 hours of incubation (3), an alternate explanation would be needed.

A preliminary report of this work has been published (10).

\section{METHODS}

The cyanmethemoglobin method, Wintrobe hematocrit (11), and Coulter electronic cell counter (12) were used to determine, respectively, the hemoglobin concentration, volume of packed red cells, and red cell count of whole blood. Isotonic and hypotonic solutions of "saline" were prepared to contain sodium chloride and sodium phosphate and were buffered at $\mathrm{pH} 7.40$, as described by Parpart and co-workers (8) and by Dacie (13). The tonicity of a given solution was recorded as the per cent of sodium chloride to which it was osmotically equivalent. For quantitative osmotic fragility determinations, 10 to $15 \mathrm{ml}$ of venous blood was taken in a dry, sterile syringe and defibrinated in a sterilized 125-ml Erlenmeyer flask closed by a screw cap or a cotton plug. From this flask, by using aseptic technic, aliquots of about 0.1 to $0.2 \mathrm{ml}$ were transferred to a small test tube immediately after defibrination (zero time) and after stated periods of incubation. Incubation was carried out at $37^{\circ} \mathrm{C}$, without shaking, in a warm air incubator. Oxygen was available from room air at an average atmospheric pressure of 655 $\mathrm{mm}$ of mercury. Without delay, $0.02 \mathrm{ml}$ of blood from the small test tube was added to $5.0 \mathrm{ml}$ of each specified isotonic or hypotonic solution, mixed by inversion, and allowed to stand 30 minutes at room temperature $\left(21^{\circ}\right.$ to $25^{\circ} \mathrm{C}$ ) to undergo osmotic lysis. After centrifugation at $4^{\circ} \mathrm{C}$ to separate non-hemolyzed cells and ghosts, the supernate was decanted and its optical density was determined at $540 \mathrm{~m} \mu$. The osmotic hemolysis in specified hypotonic solutions and the non-osmotic hemolysis of the aliquots were calculated as follows :

$$
\begin{aligned}
\text { Osmotic hemolysis in tonicity } t & =\frac{(O . D .)_{t}-(O . D .)_{i}}{(O . D .)_{o}-(O . D .)_{i}} \\
\text { Non-osmotic hemolysis } & =\frac{(O . D .)_{i}}{(O . D .)_{0}}
\end{aligned}
$$

where (O.D.) $)_{1}$ is the optical density of the tube containing $0.02 \mathrm{ml}$ blood in $5.0 \mathrm{ml}$ isotonic "saline," 1 (O.D.)。

1 When anemia was present, $4.0 \mathrm{ml}$ rather than $5.0 \mathrm{ml}$ diluent was used in all tubes. 
TABLE I

Hematological data *

\begin{tabular}{lcccc}
\hline \multicolumn{1}{c}{ Diagnosis } & Patient & VPRC & MCV & MCHC \\
\hline & & $m l / 100$ & $c \mu$ & $g / 100 m l$ \\
& P-1 & 25 & 66 & 26 \\
& P-2 & 29 & 62 & 26 \\
Iron deficiency & P-3 & 21 & 74 & 23 \\
anemia & P-4 & 31 & 71 & 29 \\
& P-5 & 17 & 52 & 24 \\
& P-6 & 35 & 65 & 25 \\
Hereditary & P-16 & 33 & 64 & 31 \\
leptocytosis & P-17 & 44 & 69 & 31 \\
& P-18 & 34 & 70 & 30 \\
Hereditary & P-19 & 43 & 59 & 33 \\
non-spherocytic & & & & \\
hemolytic anemia & P-30 & 31 & 89 & 31 \\
Hereditary & & & & \\
spherocytosis & P-31 & 50 & 75 & 37 \\
\end{tabular}

* Abbreviations: VPRC, volume of packed red cells; MCV, mean corpuscular volume; MCHC, mean corpuscular hemoglobin concen-

is the optical density of the tube containing $0.02 \mathrm{ml}$ blood in $5.0 \mathrm{ml}$ distilled water, and (O.D.) $\mathrm{t}$ is the optical density of the tube containing $0.02 \mathrm{ml}$ blood in $5.0 \mathrm{ml}$ specified hypotonic "saline."

The $\mathrm{pH}$ of the hypotonic solutions, after hemolysis occurred, was $7.40 \pm 0.05$, as measured with a Beckman model $\mathrm{H} 2 \mathrm{pH}$ meter.
Clinical material. Osmotic fragility studies were performed on 12 normal subjects and on 31 patients. Fifteen of the patients had iron deficiency anemia; 14 had hereditary leptocytosis (thalassemia minor) with increased values for $\mathrm{HbA}_{2}$; one patient, previously splenectomized, had hereditary spherocytosis; and one had hereditary non-spherocytic hemolytic anemia of the type described by Valentine, Tanaka and Miwa $(14,15)$, namely, a deficiency of the erythrocytic enzyme pyruvic kinase. Because of limitations of space and because of the similarities in the results within each group, studies will not be presented on all subjects and patients. The pertinent hematologic values on the patients on whom data are presented are given in Table I.

\section{RESULTS}

\section{Normal erythrocytes}

Influence of the tonicity and period of incubation on the osmotic fragility. The changes in the osmotic fragility of the erythrocytes of a single normal subject at various tonicities of solutions after $0,24,36,48$, and 72 hours of incubation are given in Figure 1.

After the first 24 hours of incubation there was an increase in fragility at all tonicities. During the next 24-hour period there was a decrease in fragility in the lower tonicities (less than 0.50 per

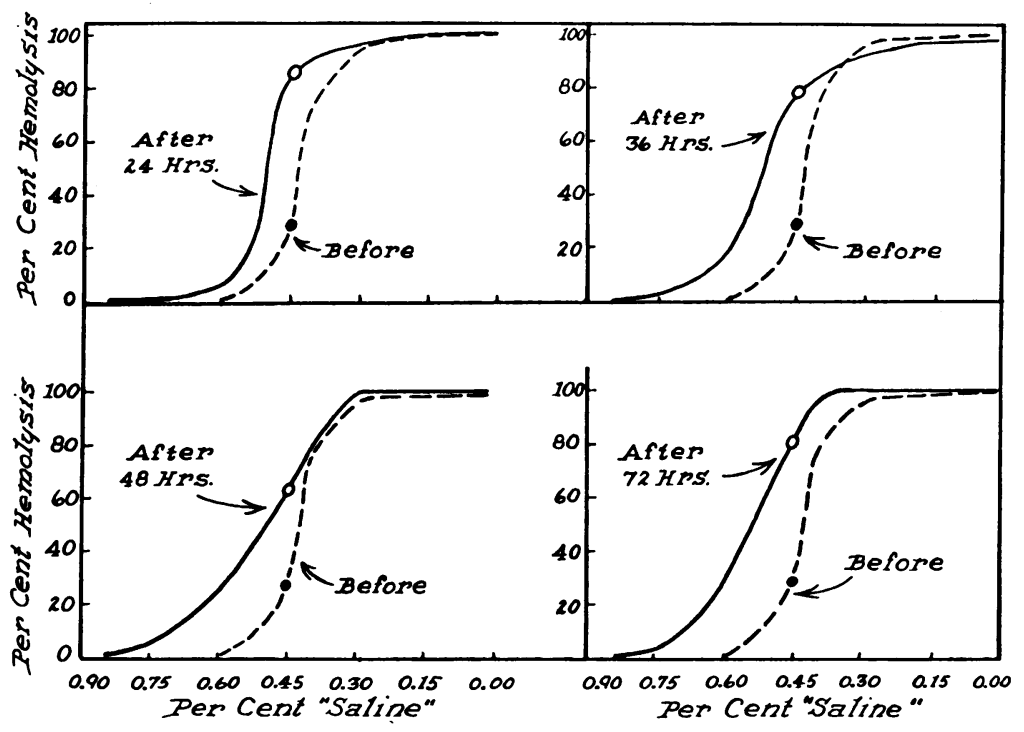

Fig. 1. OSMOTIC FRAGILITY OF THE ERYTHROCYTES OF A NORMAL SUBJECT (S-1) AT VARIOUS TONICITIES OF SOLUTIONS AFTER 0, 24, 36, 48, AND 72 HOURS of incubation. The control curve before incubation (broken line) is reproduced in each section for reference. The 0.45 per cent "saline" points are marked by $\bigcirc$ and $O$ so that the sequential changes at this tonicity can be followed. 


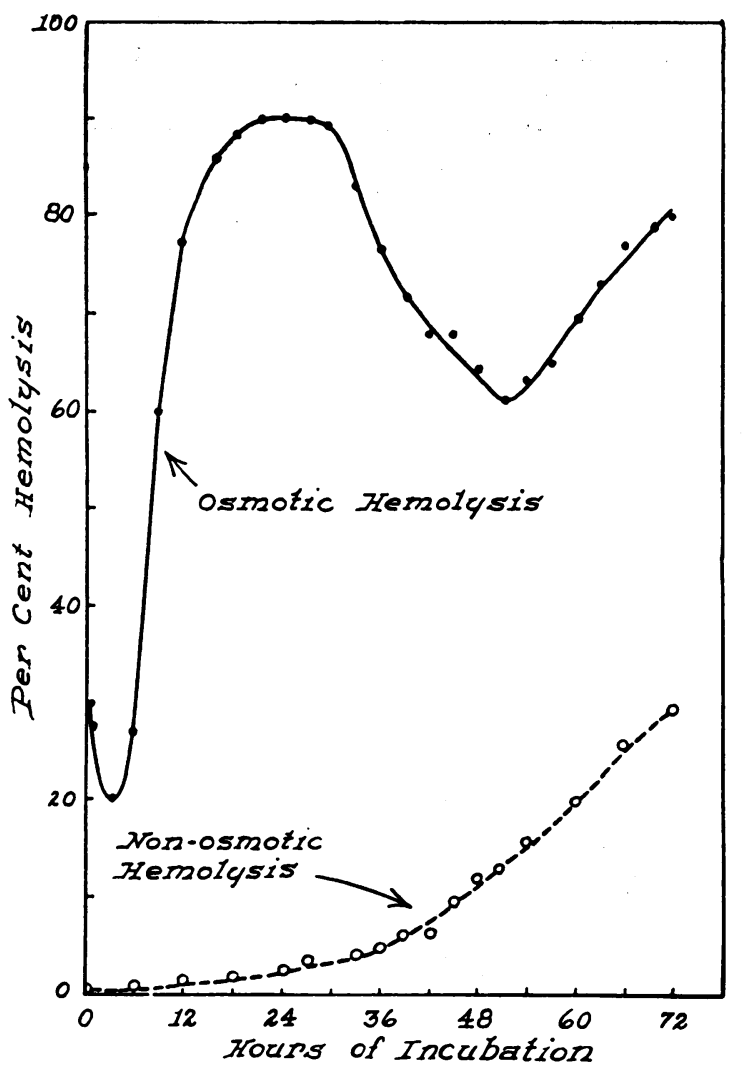

Fig. 2. Osmotic FRAgility IN 0.45 PER CENT "SALINE" OF THE ERYTHROCYTES OF A NORMAL SUBJECT (S-1) AS a function of the time of incubation. Non-osmotic hemolysis (broken line) determined on the same samples is also shown.

cent "saline") but an increase at higher tonicities ( 0.55 to 0.85 per cent). Finally, between 48 and 72 hours of incubation, there was an increase at all tonicities as compared with the fragility before incubation. This reversal in the direction of the change in osmotic fragility of normal erythrocytes can be best seen by following the changes in 0.45 per cent "saline" with time (Figure 1).

The changes in osmotic fragility of erythrocytes in 0.45 per cent "saline" at successive 3 -hour periods of incubation are plotted in Figure 2. An orderly progression of increasing (phase I), then decreasing (phase II), and finally increasing (phase III) fragility was found. This fluctuation was well beyond the experimental error of the observations, and a smooth curve could be drawn through the points, revealing a cyclic pattern. In some but not all instances there was a slight de- cline in osmotic fragility during the first 3 hours of incubation (Figure 2).

Cyclic changes in the osmotic fragility with incubation. Cyclic changes of the nature described above were found in all 12 of the normal subjects studied. The changes in erythrocyte osmotic fragility of four of the subjects are presented in Figure 3.

There was some variation in the amplitude or period of the cycle from individual to individual but the curve was reproduced well in a subject studied twice over a period of 2 months (Figure $3, D)$. In general, in 0.45 per cent "saline" there was a four fold increase in osmotic fragility in the first phase of the cycle, reaching a maximum value after 18 to 24 hours of incubation. The second phase of the cycle, starting at the first inflection point, was marked by a fall in osmotic fragility to about one-half to two-thirds of the

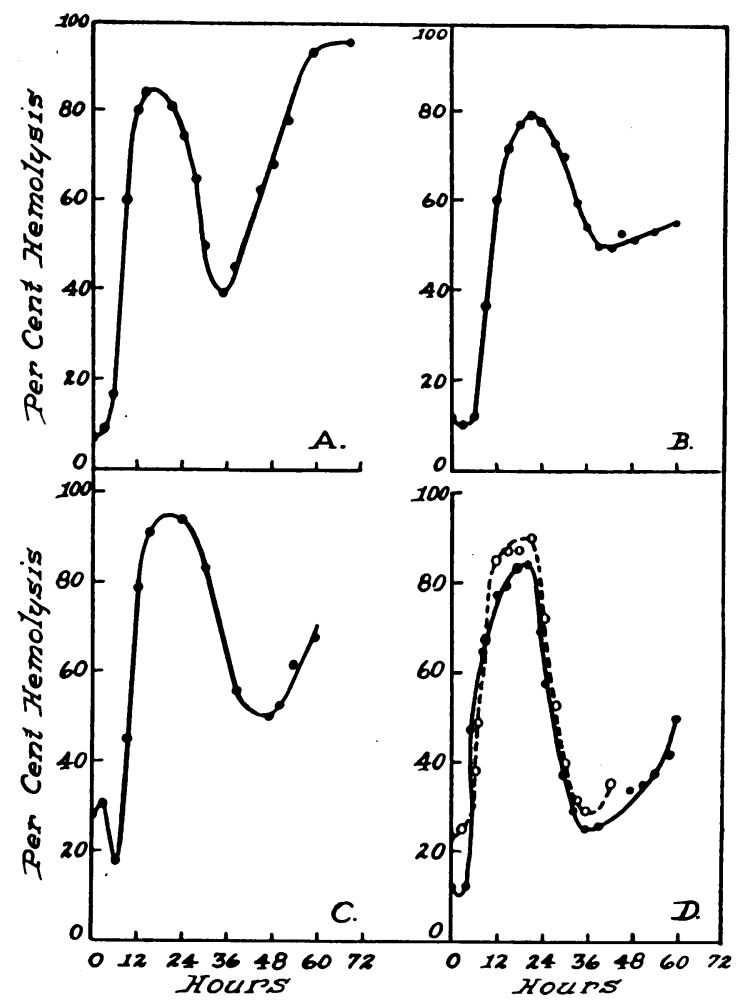

Fig. 3. OsMOtIC FRAGILITY OF THE ERYTHROCYTES OF FOUR NORMAL SUBJECTS IN 0.45 PER CENT "SALINE" AS A FUNCTION OF THE TIME OF INCUBation. A, Subject S-2; B, Subject S-3; C, Subject S-4; D, Subject S-5. The results of two studies performed two months apart on Subject S-5 (D) are shown to demonstrate the reproducibility in a given individual. 
maximum value. After 36 to 48 hours of incubation, after the second major inflection point, the third phase began and was characterized by a continuous increase in osmotic fragility. During the first phase there was a negligible loss of cells due to non-osmotic hemolysis (Figure 2). In the second phase the loss was small and insufficient to account for the change in osmotic fragility even if one were to assume selective removal of the most fragile cells by non-osmotic factors. During the third phase, non-osmotic hemolysis increased and reached values of about 30 per cent after 72 hours of incubation.

Relationship between tonicity and cyclic changes. The cyclic changes in osmotic fragility after incubation were fully revealed in hypotonic solutions which produced between 10 and 90 per cent hemolysis of the unincubated cells (Figure 4). Other tonicities produced too little or too much

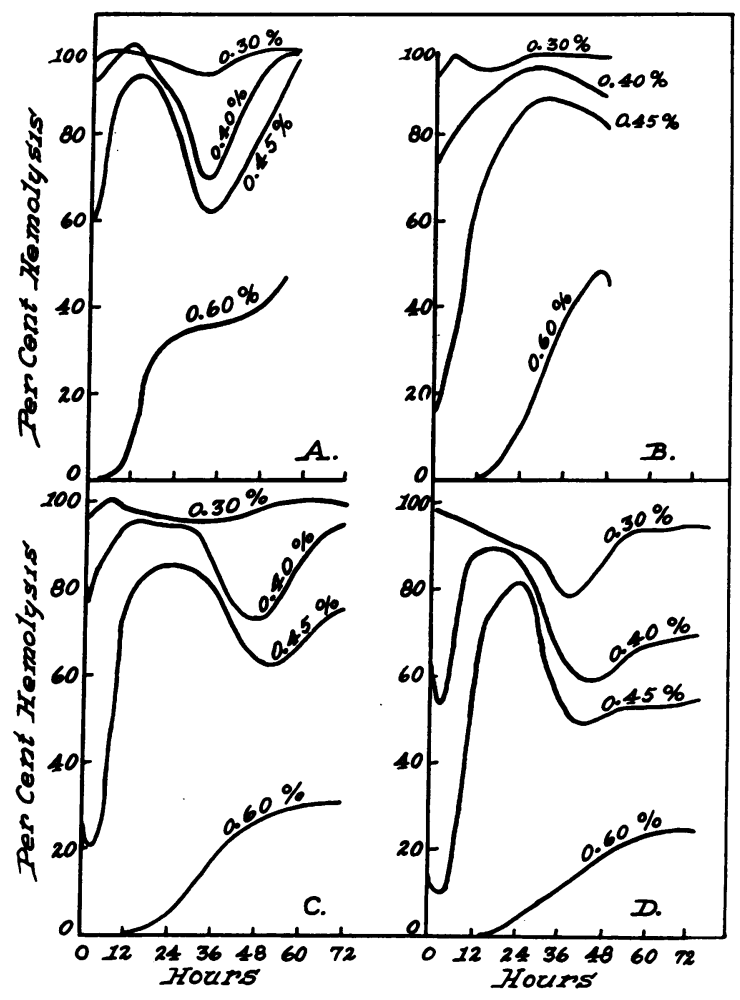

Fig. 4. OSMOTIC FRAGILITY OF THE ERYTHROCYTES OF FOUR NORMAL SUBJECTS AS A FUNCTION OF THE TIME OF INCUBATION AND THE TONICITY OF THE SOLUTION. A, Subject S-6; B, Subject S-7; C, Subject S-1; D, Subject S-3. The curves in $0.60,0.45,0.40$, and 0.30 per cent "saline" are given for each subject.
TABLE II

Effect of glucose, adenosine, and fuoride on the time of occurrence of the nadir of the osmotic fragility curve of normal erythrocytes

\begin{tabular}{|c|c|c|c|c|}
\hline \multirow[b]{2}{*}{ Subject } & \multicolumn{4}{|c|}{ Hours of incubation at nadir } \\
\hline & $\begin{array}{l}\text { No } \\
\text { additive }\end{array}$ & Glucose & Adenosine & Fluoride \\
\hline & & $8 \mu \mathrm{mole} / \mathrm{ml}$ & $10 \mu \mathrm{mole} / \mathrm{ml}$ & $\begin{array}{c}50 \\
\mu \text { mole } / \mathrm{ml}\end{array}$ \\
\hline $\begin{array}{l}\text { S-1 } \\
\text { S-2 }\end{array}$ & $\begin{array}{l}50 \\
32\end{array}$ & 46 & $\begin{array}{c}40 \\
>75^{*}\end{array}$ & 5 \\
\hline $\begin{array}{l}\text { S-3 } \\
\text { S-4 }\end{array}$ & $\begin{array}{l}40 \\
44\end{array}$ & $\begin{array}{l}50 \\
72 \dagger\end{array}$ & 65 & 6 \\
\hline S-5 & 35 & 40 & 47 & 6 \\
\hline S-6 & 33 & & & 5 \\
\hline S-7 & 54 & 56 & 68 & 6 \\
\hline
\end{tabular}

* $21.4 \mu \mathrm{mole} / \mathrm{ml}$

$+16.6 \mu \mathrm{mole} / \mathrm{ml}$.

hemolysis to make clear the cyclic changes. Within the range of suitable tonicities, the first phase was shown to advantage in 0.45 per cent "saline" since the hemolysis of unincubated cells was sufficiently low to permit demonstration of the increase in fragility during the first 24 hours of incubation. Even when the first phase was not demonstrated in 0.30 per cent "saline," the second and third phases were evident. Cyclic changes were not demonstrated with normal incubated erythrocytes in 0.60 per cent or higher tonicities of "saline."

From subject to subject, for a given tonicity, the position and amplitude of the curve on the graph varied somewhat, according to the median osmotic fragility of the unincubated erythrocytes (Figure 4,A and C). In some individuals the decline from the maximum fragility was gradual or delayed (Figure 4,B). The probable basis for this observation will be discussed later.

Effect of the addition of glucose, adenosine, and fluoride on the cyclic changes. The addition of glucose to the incubation flask did not affect the first phase of the cycle but delayed the onset of the second phase and reduced its slope so that the nadir (second inflection point) occurred later than it would otherwise (Table II). Sixteen to 20 $\mu$ mole glucose per ml blood was sufficient to delay the nadir to 72 hours of incubation or later; 8 umole per $\mathrm{ml}$ delayed the nadir by 5 to 10 hours but still allowed the third phase to occur prior to 72 hours of incubation. The effect of adenosine was similar to that of glucose (Table II; Figure 


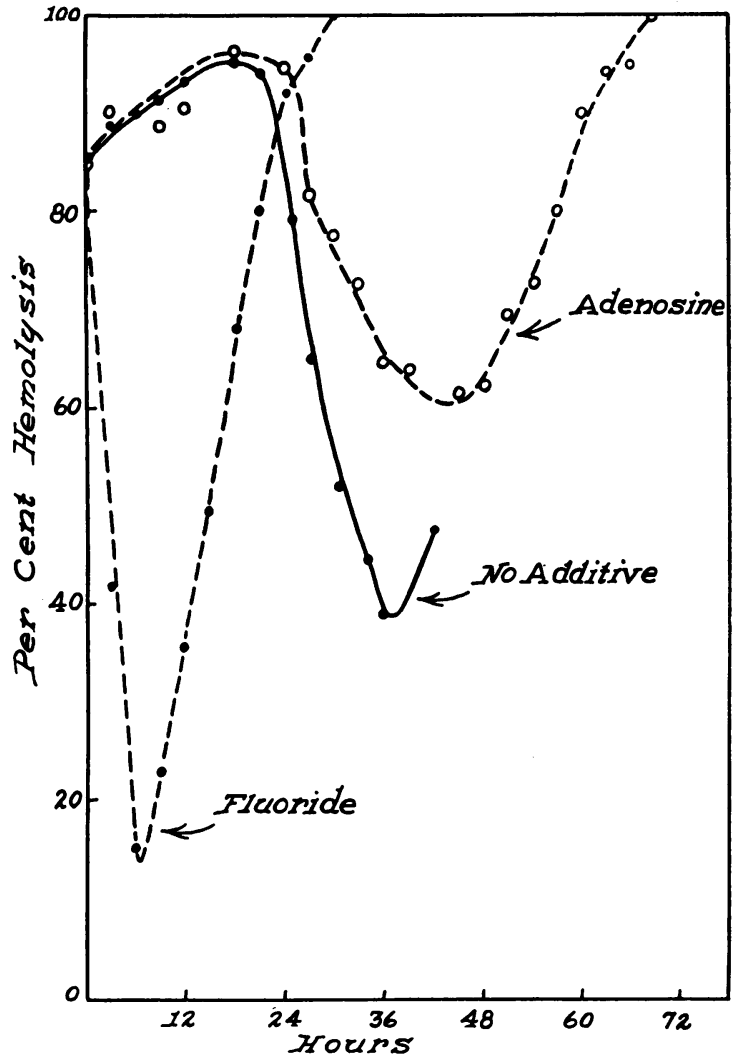

Fig. 5. The influence of Adenosine and of fluoRIDE ON THE OSMOTIC FRAGILITY OF NORMAL ERYTHROCYTES AS A Function of the time of incubation. The tonicity of the solution was 0.40 per cent "saline." Blood from Subject S-5 was incubated with adenosine, $10 \mu$ mole per $\mathrm{ml}$; with sodium fluoride, $50 \mu$ mole per $\mathrm{ml}$; or, without an additive.

5). Fluoride, on the other hand, had the opposite effect. The first phase was either abolished or greatly abbreviated. The second and third phases were unaffected, although they occurred much earlier than otherwise (Table II; Figure 5). At concentrations ranging from 6 to $70 \mu$ mole of sodium fluoride per $\mathrm{ml}$ blood in the incubation flask, the nadir occurred at about 5 to 6 hours; at 3 $\mu$ mole per $\mathrm{ml}$, the nadir occurred at 12 hours and the second phase was less prominent.

\section{Abnormal erythrocytes}

Iron deficiency. Erythrocytes from patients with iron deficiency anemia exhibited the cyclic changes observed in normal erythrocytes. Studies on 4 of the 15 subjects are presented in Figure 6.
Because of the reduced osmotic fragility of the fresh erythrocytes, it was necessary to use 0.40 per cent "saline" rather than 0.45 per cent to demonstrate the complete cycle. The differences between the response of these cells and the normal were: 1) a lesser degree of hemolysis at a given concentration of "saline" (transposition of the curve toward the abscissa) ; 2) greater prominence of the second phase with the value at the second inflection point (nadir) being less than that of unincubated erythrocytes; and 3) shortening of the period of the cycle so that the first and second inflection points occurred earlier. The last two differences distinguish the osmotic fragility of the incubated iron-deficiency erythrocytes from the normal, even when the fragility of the iron-deficiency erythrocytes was within the normal range prior to incubation (Figure 6,C and D).

Hereditary leptocytosis. The erythrocytes from patients with hereditary leptocytosis (thalassemia

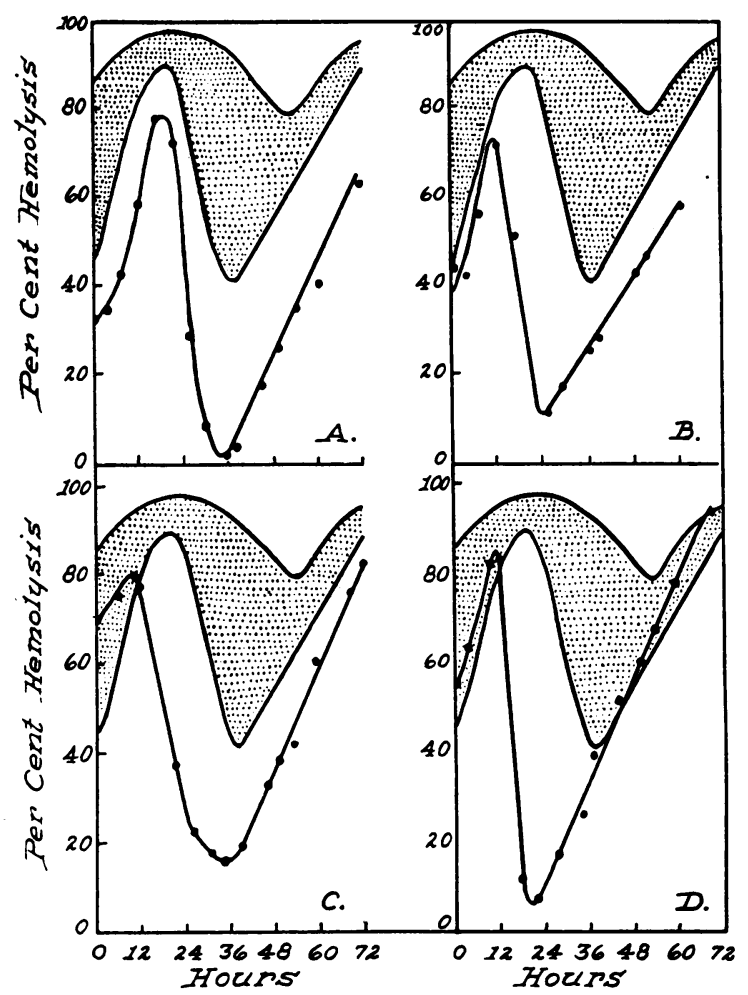

Fig. 6. Osmotic FRAGILITy IN 0.40 PER CENT "SALINE" OF THE ERYTHROCYTES OF FOUR PATIENTS WITH IRON DEFICIENCY ANEMIA AS A FUNCTION OF THE TIME OF INCUBation. A, Patient P-1; B, Patient P-2; C, Patient P-3; $D$, Patient P-4. The range of values for normal subjects is represented by the stippled area. 
minor) also exhibited a cyclic pattern in osmotic fragility after incubation (Figure 7 ). The extremely low values reached at the second inflection point (nadir) contrasted with the behavior of normal cells both at the tonicity illustrated $(0.40$ per cent "saline") and at the higher tonicities. Thus, the second phase of the cyclic pattern was greatly accentuated. In comparison with erythrocytes from patients with iron deficiency, the curve was displaced further toward the abscissa in 0.40 per cent "saline." As a result, the fact that the value of the nadir was lower than in the unincubated cells was somewhat obscured. In a more hypotonic solution, such as 0.30 per cent "saline" (Figure 8,A and $\mathrm{B}$ ), the difference between the osmotic fragility of incubated normal cells and incubated cells from patients with iron deficiency anemia or hereditary leptocytosis was shown to advantage.

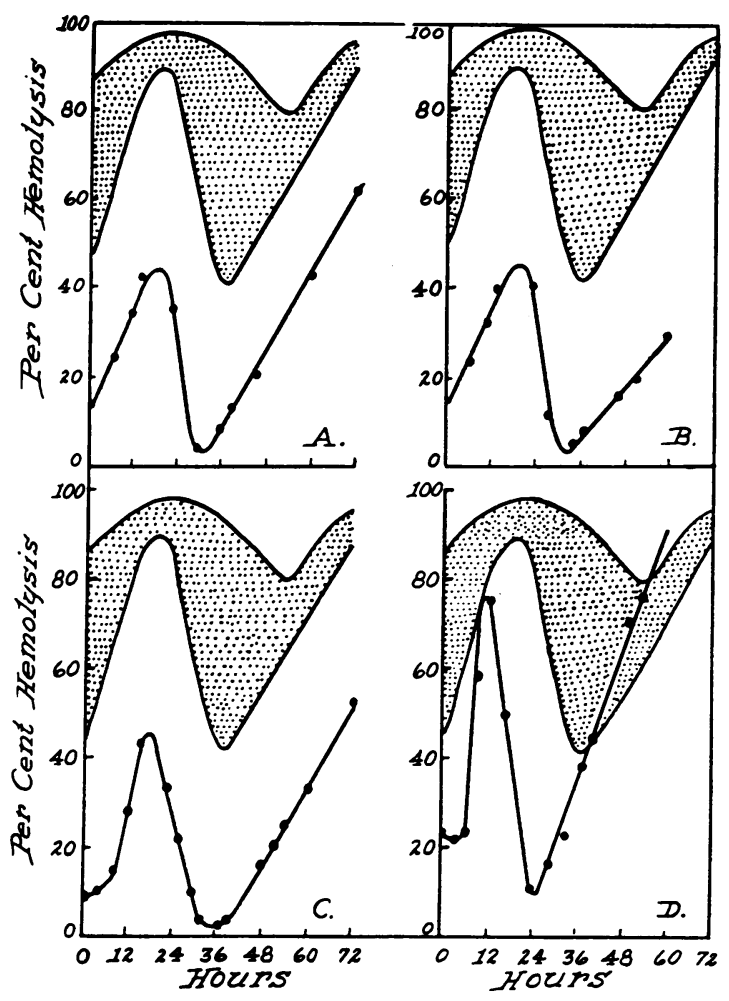

Fig. 7. Osmotic FRAGILITY IN 0.40 PER CENT "SAline" OF THE ERYTHROCYTES OF FOUR PATIENTS WITH HEREDITARY LEPTOCYTOSIS (THALASSEMIA MINOR) AS A FUNCtion of the time of incubation. A, Patient P-16; B, Patient P-17; C, Patient P-18; D, Patient P-19. The range of values for normal subjects is represented by the stippled area.

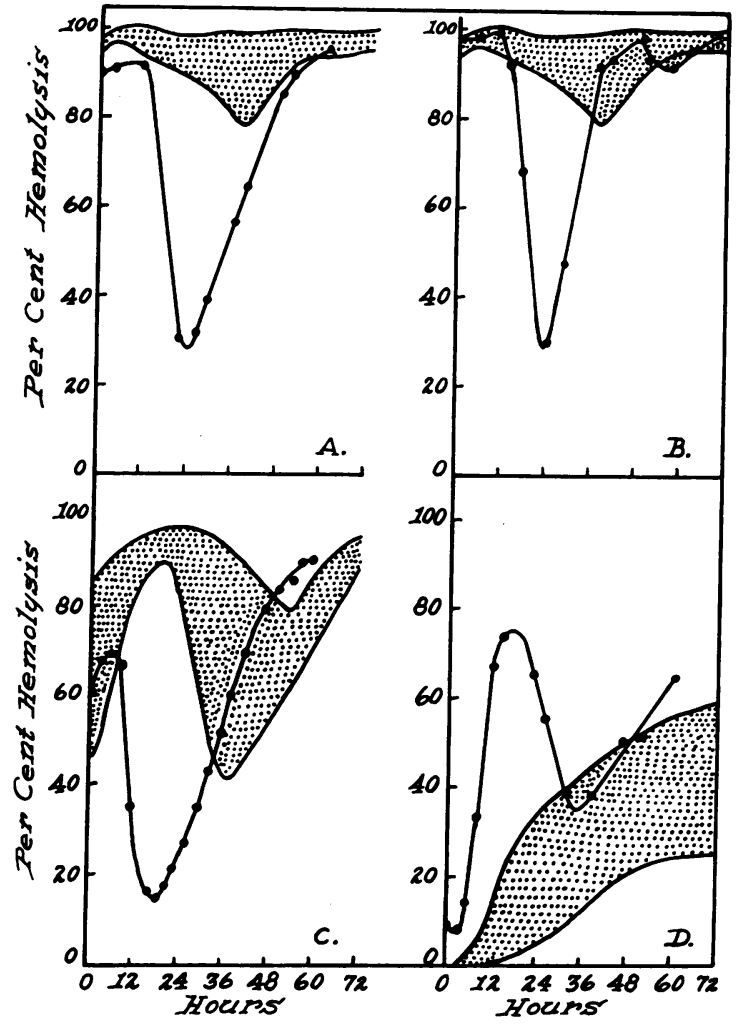

Fig. 8. Osmotic FRAgILITY AS A FUnCtion OF THE time of INCUBATION. A. ERythrocytes of a PATIENT WITH IRON DEFICIENCY ANEMIA IN 0.30 PER CENT "SALiNe." B. ERythrocytes of a patient With herediTARY LEPTOCYTOSIS IN 0.30 PER CENT “SALINE." C. ERYTHROCYTES OF A PATIENT WITH HEREDITARY NONSPHEROCYTIC HEMOLYTIC ANEMIA IN 0.40 PER CENT "SALine." D. ERYThRocytes of a PATIENT With HEREDITARY SPHEROCYTOSIS IN 0.60 PER CENT "SALINE." In each diagram, the range of values for incubated normal erythrocytes in that solution is represented by the stippled area. A, Patient P-2 ; B, Patient P-19; C, Patient P-30; D, Patient P-31.

\section{Hereditary non-spherocytic hemolytic anemia.} In a single patient with hereditary non-spherocytic anemia (Figure 8,C) due to pyruvic kinase deficiency, the first phase of the cycle was completed more rapidly than in any other type of erythrocyte studied. In other regards the curve was similar to that obtained with erythrocytes from patients with iron-deficiency anemia.

Hereditary spherocytosis. The incubated osmotic fragility curve in a patient with hereditary spherocytosis (Figure 8,D) was quite different from the normal when both were tested in 0.60 per cent "saline." However, in hereditary sphero- 
TABLE III

Effect of adenosine, glucose, and fluoride on the time of occurrence of the nadir of the osmotic fragility of abnormal erythrocytes

\begin{tabular}{|c|c|c|c|c|}
\hline Additive & Disorder & Patient & $\begin{array}{c}\text { No } \\
\text { addi- } \\
\text { tive }\end{array}$ & $\begin{array}{l}\text { With } \\
\text { addi- } \\
\text { tive }\end{array}$ \\
\hline $\begin{array}{l}\text { Adenosine, } \\
10 \mu m o l e / m l\end{array}$ & $\begin{array}{l}\text { Iron deficiency } \\
\text { anemia }\end{array}$ & P-5 & $\begin{array}{l}\text { hrs } \\
30\end{array}$ & $\begin{array}{c}\text { hrs } \\
54\end{array}$ \\
\hline $\begin{array}{l}\text { Adenosine, } \\
21 \mu m o l e / m l\end{array}$ & $\begin{array}{l}\text { Iron deficiency } \\
\text { anemia }\end{array}$ & $\mathrm{P}-2$ & 24 & 44 \\
\hline $\begin{array}{l}\text { Adenosine, } \\
21 \mu m o l e / m l\end{array}$ & $\begin{array}{l}\text { Iron deficiency } \\
\text { anemia }\end{array}$ & P-6 & 34 & $>72$ \\
\hline $\begin{array}{l}\text { Adenosine, } \\
25 \text { mmole } / m l\end{array}$ & Hereditary leptocytosis & P-18 & 34 & $>76$ \\
\hline $\begin{array}{l}\text { Glucose, } \\
17 \mu m o l e / m l\end{array}$ & $\begin{array}{l}\text { Hereditary sphero- } \\
\text { cytosis }\end{array}$ & P-31 & 33 & 46 \\
\hline $\begin{array}{l}\text { Fluoride, } \\
50 \mu \text { mole } / \mathrm{ml}\end{array}$ & $\begin{array}{l}\text { Hereditary sphero- } \\
\text { cytosis }\end{array}$ & P-31 & 33 & $<1$ \\
\hline $\begin{array}{l}\text { Fluoride, } \\
60 \text { mmole } / \mathrm{ml}\end{array}$ & $\begin{array}{l}\text { Hereditary non-sphero- } \\
\text { cytic hemolytic anemia }\end{array}$ & P-30 & 18 & 5 \\
\hline
\end{tabular}

cytosis studied in 0.60 per cent "saline," the curve resembled that of normal erythrocytes studied at a lower tonicity (Figure 3). The presence of the second phase, normal in proportion, contour, and value at the nadir, relative to the hemolysis of unincubated red cells, is of special interest.

Effect of the addition of glucose, adenosine, and fluoride on the cyclic changes. Abnormal erythrocytes responded to the addition of glucose, adenosine, and fluoride (Table III) as did normal cells, with one exception. When fluoride was added to the cells from the patient with hereditary spherocytosis, the effect was greatly exaggerated. The slope of the second phase was increased to even a greater extent than in normal cells (Figure 5$)$, and the nadir was reached in 1 hour or less rather than in 5 to 6 hours. The third phase was virtually completed after 4 hours of incubation.

\section{DISCUSSION}

Normal and abnormal erythrocytes exhibited a three-phase, cyclic pattern of change in osmotic fragility during aseptic incubation, rather than one which was unidirectional, as suggested by conventional observations made after 24 hours of incubation. Abnormal erythrocytes were distinguished by alterations in the period of the cycle, the amplitude of the second phase, or the tonicity at which maximum amplitude was observed.

The first phase of the cyclic pattern appeared to be dependent on continuing glycolysis. It was abolished by the addition of fluoride in amounts which inhibit glycolysis, and it was abbreviated in pyruvic kinase deficiency. Conversely, addition of glucose or adenosine in sufficient quantity prolonged the terminal portion of the first phase and replaced the first inflection point with a plateau. The means by which glycolysis produced this alteration was not investigated. The accumulation of lactic acid and a fall in intracellular $\mathrm{pH}$ might be one explanation. Others have reported an accumulation of cation and an increase in mean cell volume (16) during the first 24 hours of incubation. These changes probably reflected the same phenomena measured by the osmotic fragility.

The slight decline in osmotic fragility during the first 3 hours observed in some but not all instances might be the result of an increase in intracellular $\mathrm{pH}$ even though the cells were diluted 251 times by the addition of buffered medium. This rise in $\mathrm{pH}$ may have resulted from the release of ammonia which is known to occur soon after blood is withdrawn.

The second phase of the cycle was probably due to the cessation of glycolysis. The early appearance of the second phase after the addition of fluoride to the incubation flask and the delay of the second phase brought about by the addition of glucose support this contention. Temporally, the second phase coincided with a period of rapid loss of potassium from the incubated erythrocytes and a decrease in the mean cell volume $(16,17)$. Glucose has delayed the onset of potassium loss (16. 18) and fluoride has advanced it (19-22). This suggests that in the initiation of the second phase the sequence was: the cessation of glycolysis, rapid loss of intracellular potassium and then water, a decline in cell volume, and a consequent decrease in osmotic fragility.

The reduced slope of the second phase and the delay in the occurrence of the nadir noted in some normal subjects (Figure 4,B) may have been due to variations in the blood sugar at the time samples were obtained.

The increase in osmotic fragility in the third phase was accompanied by a significant increase in non-osmotic hemolysis. Both of these events may be associated with the fall in the concentration of adenosine triphosphate which follows upon the cessation of glycolysis $(23,24)$. Apparently the permeability of the red cell membrane is altered when glycolysis ceases (25). 
Both glucose and fluoride bring about an increase in osmotic fragility about 12 to 18 hours after their addition to the incubation flask. The effects may be distinguished as a late first-phase phenomenon in the case of glucose and a thirdphase event in the case of fluoride, on the basis of the non-osmotic hemolysis which is proportionately small in the case of glucose and proportionately large in the case of fluoride.

In these studies the effect of added adenosine was similar to that of glucose in increasing osmotic fragility of erythrocytes incubated in their own serum. This contrasts with observations on washed erythrocytes incubated in phosphate buffer at $37^{\circ} \mathrm{C}(26)$ and on erythrocytes stored at $4^{\circ} \mathrm{C}$ in their own plasma (23). The differences in the experimental conditions cited probably account for this contrast.

The results we have discussed reflect the mean changes for a population of erythrocytes of all ages. However, a relationship between the age of erythrocytes and their resistance to hypotonic lysis has been described (27). The absence of a distinct three phase cyclic change in normal erythrocytes at tonicities greater than 0.50 per cent "saline" might be the result of the oldest erythrocytes exhibiting only a single phase. The oldest cells are most susceptible to hypotonic lysis and might respond with the equivalent of a third phase change alone.

The changes in osmotic fragility after 24 hours of incubation which characterize certain abnormal types of erythrocytes can be interpreted in the light of these observations.

In hereditary spherocytosis the cyclic pattern was normal in configuration and amplitude and was equivalent to the pattern from normal erythrocytes simply transposed from 0.45 per cent "saline" to 0.60 per cent "saline" as the test solution. This suggests that, in this disorder, geometrical considerations of the spherocyte as an osmometer, rather than metabolic abnormalities during incubation, underlie the altered osmotic fragility. Significantly, spherocytes did not pursue a relentless course of increasing osmotic fragility but, in the interval between 24 and 36 hours of incubation, exhibited the second phase, that is, decreasing osmotic fragility, as did normal erythrocytes. On the other hand, differing from the normal, the nonosmotic hemolysis of incubated spherocytes (so called, autohemolysis) was increased. Whereas glucose reduced the non-osmotic hemolysis, it did not reduce the osmotic hemolysis.

The apparently paradoxical response of leptocytes after incubation (3) was found to be parit of the normal cyclic pattern. Leptocytes exhibited an accelerated pattern, displaced to a lower than usual tonicity, and notable for accentuation of the second phase. As a result, after about 24 hours of incubation, the osmotic fragility of leptocytes in 0.40 per cent and particularly in 0.30 per cent "saline" was near a minimum value and was less than the pre-incubation value. The leptocytes had already passed through and beyond the point of maximum osmotic fragility which would only then be achieved by normal erythrocytes. Thus, the net decrease in the osmotic fragility of leptocytes $(3,17)$ and erythrocytes from some cases of hereditary non-spherocytic hemolytic anemia (16) incubated for 24 hours was not the result of a fundamentally different mechanism, even though the result contrasted sharply with the behavior of normal cells.

The early occurrence of the second phase may not have the same basis in cases of hereditary leptocytosis, iron deficiency anemia, and the form of hereditary non-spherocytic hemolytic anemia due to pyruvic kinase deficiency. With regard to glycolysis, early occurrence of the second phase might result from a low blood sugar, low intra-erythrocytic glucose, diminished entry of glucose into the erythrocyte from the serum, accelerated utilization of available glucose, or faulty metabolism of glucose. The last mentioned probably applies to the patient with pyruvic kinase deficiency. There is no evidence to relate the other possibilities to erythrocytes from iron deficiency anemia or hereditary leptocytosis. As an alternative, one may relate early occurrence of the second phase to the ease with which equilibrium is established between the intra-erythrocytic and extra-erythrocytic cation pools, once the metabolic mechanism for maintaining a high intra-erythrocytic potassium concentration is exhausted. Erythrocytes with the greater surface-area-to-volume ratio (9) would reach equilibrium more rapidly than those with a lower ratio. According to this view, leptocytes would be expected to lose potassium and water and reach equilibrium with serum potassium concentration more rapidly than would normal eryth- 
rocytes or spherocytes. Cation loss would proceed rapidly so that maximal change in mean cell volume and reduction in osmotic fragility could occur before the opposing forces of the third phase act to increase osmotic fragility once again.

It would seem fortunate that 24 hours of incubation was selected to differentiate the osmotic fragility of abnormal erythrocytes in the classical incubated osmotic fragility test. At 12 hours of incubation, normal and leptocytic cells would not be differentiated and at 36 hours of incubation the difference between normal cells and spherocytes would probably be obscured (3).

\section{SUMMARY}

1. Normal and abnormal erythrocytes, during aseptic incubation at $37^{\circ} \mathrm{C}$ in their own serum over a period of 72 hours, underwent a threephase, cyclic change in osmotic fragility.

2. Normally, the first phase, characterized by increasing osmotic fragility, occurred during the first 24 hours; the second phase, in which fragility decreased, occurred in the next 24 hours; the third phase, a return to increasing fragility, followed in the next 24-hour period.

3 . The amplitude of the cyclic change depended upon the tonicity in which the osmotic fragility was determined. Abnormal erythrocytes exhibited changes in the period of the cycle, the amplitude of the cycle, or the tonicity at which maximum amplitude was observed.

4. The addition of glucose or adenosine to the incubation serum delayed the onset of the second phase; fluoride abolished the first phase and advanced the occurrence of the second phase.

5. It is postulated that the first phase may be due to continuing glycolysis, the second phase to erythrocytic cation loss upon cessation of glycolysis, and the third phase to depletion of erythrocytic adenosine triphosphate. It is also suggested that the variations in osmotic fragility observed after incubation of spherocytes, leptocytes, and iron deficiency erythrocytes are related to the ratio of surface area to volume of each of these cell types.

\section{ACKNOWLEDGMENTS}

We are indebted to Miss Doris Kurth, Mrs. Janet Anderson, and $\mathrm{Mr}$. Thomas Caine for technical assistance.

\section{REFERENCES}

1. Young, L. E. Hemolytic disorders : recent advances in diagnosis, prevention, and treatment. N. Y. St. J. Med. 1947, 47, 1875.

2. Ham, T. H., and Castle, W. B. Relation of increased hypotonic fragility and of erythrostasis to the mechanism of hemolysis in certain anemias. Trans. Ass. Amer. Phycns 1940, 55, 127.

3. Haut, A., Kurth, D., Cartwright, G. E., and Wintrobe, M. M. Osmotic fragility of incubated leptocytes. Submitted for publication.

4. Williams, T. F., Fordham, C. C., III, Hollander, W., Jr., and Welt, L. G. A study of the osmotic behavior of the human erythrocyte. J. clin. Invest. 1959, 38, 1587.

5. Hoffman, J. F. Physiological characteristics of human red blood cell ghosts. J. gen. Physiol. 1958, 42, 9.

6. Castle, W. B., and Daland, G. A. Susceptibility of erythrocytes to hypotonic hemolysis as a function of discoidal form. Amer. J. Physiol. 1937, 120, 371.

7. Hoffman, J. F., Eden, M., Barr, J. S., Jr., and Bedell, R. H. S. The hemolytic volume of human erythrocytes. J. cell. comp. Physiol. 1958, 51, 405.

8. Parpart, A. K., Lorenz, P. B., Parpart, E. R., Gregg, J. R., and Chase, A. M. The osmotic resistance (fragility) of human red cells. J. clin. Invest. 1947, 26, 636.

9. Crosby, W. H. Pathogenesis of spherocytes and leptocytes (target cells). Blood 1952, 7, 261.

10. Haut, A., Cartwright, G. E., and Wintrobe, M. M. Cyclic variation of osmotic fragility during incubation of RBC. Clin. Res. 1960, 8, 102.

11. Wintrobe, M. M. Clinical Hematology, 5th ed., Philadelphia, Lea and Febiger, 1961.

12. Brecher, G., Schneiderman, M., and Williams, G. Z. Evaluation of electronic red blood cell counter. Amer. J. clin. Path. 1956, 26, 1439.

13. Dacie, J. V. The Hemolytic Anemias, 1st ed. New York, Grune \& Stratton, 1954, p. 476.

14. Valentine, W. N., Tanaka, K. R., and Miwa, S. A specific erythrocyte glycolytic enzyme defect (pyruvate kinase) in three subjects with congenital non-spherocytic hemolytic anemia. Trans. Ass. Amer. Phycns 1961, 74, 100.

15. Tanaka, K. R., Valentine, W. N., and Miwa, S. Pyruvate kinase $(\mathrm{PK})$ deficiency hereditary nonspherocytic hemolytic anemia. Blood 1962, 19, 267.

16. Selwyn, J. G., and Dacie, J. V. Autohemolysis and other changes resulting from the incubation in vitro of red cells from patients with congenital hemolytic anemia. Blood 1954, 9, 414.

17. Selwyn, J. G. Unpublished observations (1953), cited in J. V. Dacie, The Hemolytic Anemias, Congenital and Acquired. Part I. The Congenital Anemias, 2nd ed. New York, Grune \& Stratton, 1960, p. 206. 
18. Parpart, A. K., and Green, J. W. The effect of glucose and $\mathrm{pH}$ upon potassium loss from rabbit red cells. J. cell. comp. Physiol. 1953, 42, 179.

19. Wilbrandt, W. A relation between permeability of the red cell and its metabolism. Trans. Faraday Soc. 1937, 33, 956.

20. Wilbrandt, W. Die Abhängigkeit der Ionenpermeabilität der Erythrocyten vom glykolytischen Stoffwechsel. Pflüger's Archiv. 1940, 243, 519.

21. Green, J. W., and Parpart, A. K. The effect of metabolic poisons on potassium loss from rabbit red cells. J. cell. comp. Physiol. 1953, 42, 191.

22. Eckel, R. E. Potassium exchange in human erythrocytes. I. General aspects of the fluoride effect. J. cell. comp. Physiol. 1958, 51, 81.

23. Gabrio, B. W., Finch, C. A., and Huennekens, F. M. Erythrocyte preservation: a topic in molecular biochemistry. Blood 1956, 11, 103.
24. Lindemann, B., and Passow, H. Versuche zur Aufklärung der Beziehung zwischen Glucolysehemmung und Kaliumverlust bei der Fluoridvergiftung von Menschenerythrocyten. Pflüger's Archiv. 1960, 271, 497.

25. Dacie, J. V. The Hemolytic Anemias. Part I. The Congenital Anemias, 2nd ed. New York, Grune \& Stratton, 1960.

26. Jaffé, E. R., Lowy, B. A., Vanderhoff, Grace, A., Aisen, P., and London, I. M. The effects of nucleosides on the resistance of normal human erythrocytes to osmotic lysis. J. clin. Invest. 1957, 36, 1498.

27. Jaffé, E. R., Vanderhoff, Grace A., Lowy, B. A., and London, I. M. The relationship of the age of rabbit erythrocytes to the effects of inosine on their osmotic resistance. J. clin. Invest. 1958, 37, 1293. 